\title{
Clinical and hormonal findings in patients presenting with high IGF-1 and growth hormone suppression after oral glucose load: a retrospective cohort study
}

\section{Giulia Carosi@1,2, Alessandra Mangone ${ }^{3}$, Elisa Sala', Giulia Del Sindaco ${ }^{1,3}$, Roberta Mungari', Arianna Cremaschi ${ }^{1,3}$, Emanuele Ferrante', Maura Arosio ${ }^{1,3}$ and Giovanna Mantovani ${ }^{1,3}$}

${ }^{1}$ Endocrinology Unit, Fondazione IRCCS Cà Granda Ospedale Maggiore Policlinico, Milan, Italy, ${ }^{2}$ Department of Experimental Medicine, Sapienza University of Rome, Rome, Italy, and ${ }^{3}$ Department of Clinical Sciences and Community Health, University of Milan, Milan, Italy
Correspondence should be addressed to G Mantovani Email

giovanna.mantovani@unimi.it

\begin{abstract}
Objective: High insulin-like growth factor 1 (IGF-1) and unsuppressed growth hormone (GH) levels after glucose load confirm the diagnosis of acromegaly. Management of patients with conflicting results could be challenging. Our aim was to evaluate the clinical and hormonal evolution over a long follow-up in patients with high IGF-1 but normal GH nadir ( $\mathrm{GHn}<0.4 \mu \mathrm{g} / \mathrm{L}$ according to the latest guidelines).

Design: Retrospective cohort study.

Methods: We enrolled 53 patients presenting high IGF-1 and GHn $<0.4 \mu \mathrm{g} / \mathrm{L}$, assessed because of clinical suspicion of acromegaly or in other endocrinological contexts (e.g. pituitary incidentaloma). Clinical and hormonal data collected at the first and last visit were analyzed.

Results: At the first evaluation, the mean age was $54.1 \pm 15.4$ years, 34/53 were females, median IGF-1 and GHn were +3.1 SDS and $0.06 \mu \mathrm{g} / \mathrm{L}$, respectively. In the whole group, over a median time of 6 years, IGF-1 and GHn levels did not significantly change (IGF-1 mean of differences: $-0.58, P=0.15 ; \mathrm{GHn}+0.03, P=0.29$ ). In patients with clinical features of acromegaly, the prevalence of acromegalic comorbidities was higher than in the others (median of 3 vs 1 comorbidities per patient, $P=0.005)$, especially malignancies ( $36 \%$ vs $6 \%, P=0.03)$, and the clinical worsening overtime was more pronounced (4 vs 1 comorbidities at the last visit).

Conclusions: In patients presenting high IGF-1 but GHn $<0.4 \mu \mathrm{g} / \mathrm{L}$, a hormonal progression is improbable, likely excluding classical acromegaly in its early stage. However, despite persistently low GH nadir values, patients with acromegalic features present more acromegalic comorbidities whose rate increases over time. Close clinical surveillance of this group is advised.
\end{abstract}

\section{Introduction}

Acromegaly is a rare disease resulting from chronic exposure to high levels of growth hormone $(\mathrm{GH})$ and its main mediator, insulin-like growth factor 1 (IGF1). Almost all patients have a GH-secreting pituitary adenoma which is a macroadenoma in about $70 \%(1,2,3)$.
Increased morbidity and mortality are well documented in patients with active disease, mainly due to cardiovascular, neoplastic, respiratory, and metabolic comorbidities $(3,4,5,6)$. Therefore, a prompt therapeutic approach is mandatory. Printed in Great Britain

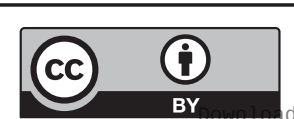

This work is licensed under a Creative Commons Attribution 4.0 International License. 
The evaluation of IGF-1 is recommended as a screening test for acromegaly. In the presence of high IGF1 , the diagnosis has to be confirmed by an inadequate $\mathrm{GH}$ suppression after an oral glucose tolerance test (OGTT). Diagnostic criteria changed over time as more sensitive assays for GH measurement have become widely available, leading to lower GH nadir (GHn) reference values, up to 0.4 $\mu \mathrm{g} / \mathrm{L}$ (2). OGTT is generally diagnostic in the majority of patients. However, some series reported acromegalic patients with adequate $\mathrm{GH}$ suppression (7, 8, 9, 10, 11, 12, 13).

In 2002, Barkan and co-workers introduced the term 'micromegaly', describing a group of patients with classical acromegalic features, high IGF-1 but normal mean GH and GHn (14). Since then, other studies reported similar patients, according to various GHn reference values $(7,8,9,10,11$, $12,13)$, ranging from 2 to $0.4 \mu \mathrm{g} / \mathrm{L}$. Interestingly, a pituitary adenoma was not identified in all cases, leading to speculation on the disease's pathophysiology (i.e. enhanced GH receptor activity), but many data on the clinical significance of this condition are still lacking. Moreover, a systematic clinical and hormonal assessment of these patients and data on the possible disease progression over time are not yet available. Therefore, the management remains challenging.

Besides the suspicion of acromegaly, IGF-1 levels are often measured in other clinical contexts, as in the presence of incidentally discovered pituitary neoplasms (15). We know that IGF-1 assessment harbors some limitations such as the lack of adequate age-adjusted normative data and susceptibility to interference from IGF-binding proteins (IGFBP) (16). Thus, clinicians frequently face unexpected high values despite no signs of $\mathrm{GH}$ hypersecretion. An apparent low incidence of acromegalic features and comorbidities seems to confirm the absence of disease in this setting (9).

The main aim of the present study was to characterize a large group of patients presenting with GH/IGF-1 discrepancy (high IGF-1 levels but suppressed GH values according to the most recent guidelines) (2), both with and without an initial suspicion of acromegaly. We focused our attention on representative comorbidities of acromegaly and GH/IGF-1 hormonal assessment, and we evaluated the evolution of all cited parameters over a long follow-up period to identify the best management of these patients.

\section{Subjects and methods}

\section{Patients}

We analyzed the data of a group of adult patients referred to a single tertiary Endocrinology Unit (Fondazione
IRCCS Ca' Granda Ospedale Maggiore Policlinico, Milan), between 2008 and 2019, presenting with IGF-1/ GH discrepancy (high IGF-1 in at least two occasions in the presence of an adequate GH nadir). A GH nadir of 0.4 $\mu \mathrm{g} / \mathrm{L}$ was considered as the reference cut-off according to recent data and guidelines $(2,17,18)$. We included patients who had been hormonally evaluated both for suspected acromegaly and in other clinical contexts (e.g. pituitary neoplasms). All conditions which may alter the GH-IGF-1 axis such as pregnancy, hepatic and renal failure, chronic inflammation, malnutrition, or oral estrogen therapy (19, $20,21)$ are represented as exclusion criteria.

\section{Study design and methods}

We used medical records to retrospectively and longitudinally investigate data collected at the time of diagnosis (first finding of a discrepancy) and at the last available visit.

Hormonal data included IGF-1, GHn, and GH random levels (GHr). GHr was assessed fasting in the morning, before starting OGTT. GHn was defined as the lowest GH value at any time during 2-hour OGTT (blood samples for GH were collected at 30, 60, 90, 120 min after glucose load).

The presence of acromegalic signs and symptoms (acromegalic facies, acral enlargement, headache, paraesthesia, hyperhidrosis, and arthralgia) were collected along with the diagnosis of typical comorbidities including goiter, arterial blood hypertension, cardiopathy (counting history of congestive heart failure, evidence of ventricular hypertrophy, diastolic/systolic dysfunction, or mitral/aortic abnormalities on echocardiography), colonic polyps, malignant neoplasms, carpal tunnel, and glucose metabolism alterations (GMA) (22, 23, 24, 25, 26, 27). According to the international criteria, we considered in GMA impaired fasting glucose (IFG), impaired glucose tolerance (IGT), and diabetes mellitus (DM) $(2,28)$. Insulin resistance has been determined by HOMA index calculation (HOMA-IR) according to the formula: fasting insulin $(\mathrm{mU} / \mathrm{L}) \times$ fasting glucose $(\mathrm{nmol} / \mathrm{L}) / 22.5$ (29). We also included BMI as an anthropometric parameter (weight in kilograms divided by the square of height in meters).

The suspicion of acromegaly, based on the presence of acromegalic features (physical changes including the prominence of brow, prognathism, macroglossia, acral overgrowth, nose, and lips enlargement), was determined by three board-certified experts in endocrinology with at least 5 years of clinical practice in this field.

In addition, we included the results of MRI of the sellar region before and after gadolinium contrast. We registered 
the presence of pituitary adenomas, empty sella, and other nonspecific alterations such as pituitary stalk deviation or sellar floor depression.

To better characterize patients with 'micromegaly', as defined by previous authors $(9,11,14)$, patients with typical acromegalic features (group 1, GR1) were separately analyzed and compared with the others (group 2, GR2).

The Local Ethical Committee (Comitato Etico Milano Area 2) approved this protocol study.

\section{Assays}

GH was assayed by a chemiluminescence method (Immulite 2000, Siemens Medical Solutions Diagnostics, detection limit of $0.01 \mu \mathrm{g} / \mathrm{L}$ ). Standards used for calibration were IS 80/505 from 2008 to July 2010 and IS 98/574 from August 2010. IGF-1 levels were measured by a chemiluminescent immunometric assay (Immulite 2000 IGF-1; Siemens Medical Solutions Diagnostics), and standards used for calibration were IRR 87/518 from 2008 to April 2017 and IS 02/254 from May 2017. IGF-1 values were expressed in standard deviation scores (SDS). We obtained SDS values accordingly to the methods provided by Chanson and colleagues (30).

\section{Statistical analysis}

We described continuous parameters with normal distribution as mean \pm S.D. and non-Gaussian distributions as median with interquartile range (IQR). Continuous and non-Gaussian data were compared using $t$-test and Wilcoxon-Mann-Whitney test, respectively. Categorical data were presented as percentage (\%), proportion (/) and analyzed using the Chi-squared test or Fisher's exact test if the expected value was $<5$. For statistical calculation, $\mathrm{GH}$ values $<0.05 \mu \mathrm{g} / \mathrm{L}$ were arbitrarily set to $0.04 \mu \mathrm{g} / \mathrm{L}$. To investigate the association of GH levels with the number of comorbidities, Spearman's correlation analysis was conducted. One-way ANOVA test for linear trend was used to compare GHn levels among five groups sub-divided based on comorbidities' number. ROC analysis assessed threshold values of $\mathrm{GHn}$ that detect patients with numerous comorbidities. The optimum sensitivity and specificity were determined using the Youden index (J). $P$-values $<0.05$ were considered statistically significant. All statistical analyses were performed using SPSS, version 24 (IBM).

\section{Results}

\section{Hormonal and clinical data of the entire population}

We selected 53 patients, $64.2 \%$ females and $35.8 \%$ males, with an average age at diagnosis of $54.1 \pm 15.4$ years (range: $20-80)$. Twenty-four females $(70.6 \%)$ were postmenopausal. Mean BMI was $27 \pm 4.3 \mathrm{~kg} / \mathrm{m}^{2}$ and HOMA-IR was $2.2 \pm 1.2$.

In $25 / 53$ patients (47.2\%), IGF-1 levels were evaluated because of clinical suspicion of acromegaly. The other 28 patients $(52.8 \%)$ had IGF-1 measured for a variety of reasons, including seven pituitary adenomas (5 pituitary incidentalomas, macroadenomas conditioning neuroophthalmological symptoms), 11 suspected hypopituitarism (4 hypogonadism, 3 hypothyroidism, 2 GH-deficiency, 1 diabetes insipidus, 1 hypoadrenalism), three empty sella, one suspected Cushing disease, one sellar meningioma, one hyperprolactinemia, four other endocrinopathies (1 hyperandrogenism, 1 MEN-1, 1 adrenal tumor, 1 thyroid cancer). Hypopituitarism was excluded in all cases except for two patients with hypogonadism.

At diagnosis, IGF-1 in the whole group was +3.1 SDS $(+2.5$ to +4.0$)$, median GHr $1.1 \mu \mathrm{g} / \mathrm{L}(0.18-2.5)$ and GHn $0.06 \mu \mathrm{g} / \mathrm{L}(0.05-0.16)$. GHr and GHn levels were higher in females (F) than in males $(\mathrm{M})$ : $\mathrm{GHr}(\mathrm{F})=1.7 \mu \mathrm{g} / \mathrm{L}(0.9-3.2)$, $(\mathrm{M})=0.15 \mu \mathrm{g} / \mathrm{L}(0.05-0.76), P<0.0001 ; \mathrm{GHn}(\mathrm{F})=0.1 \mu \mathrm{g} / \mathrm{L}$ (0.05-0.2), (M) =0.05 (0.04-0.09), $P=0.04$, as expected (31).

Taken as a whole group, typical symptoms of acromegaly were distributed as follows: arthralgia in $28.3 \%$, paraesthesia in $24.5 \%$, headache in $20.8 \%$, and hyperhidrosis in $9.4 \%$ of subjects. Acral enlargement was reported in 50.9\%. The median number of comorbidities per patient was 2 (IQR: 1-3.5). Among acromegalic comorbidities, we registered glucose metabolism alterations in 36/53 (67.9\%) patients (13 IFG, 20 IGT, and 13 $\mathrm{DM})$, hypertension in $43.4 \%$, goiter in $35.8 \%$, cardiopathy in $26.4 \%$, carpal tunnel in $18.9 \%$, malignant neoplasms in $18.9 \%$, and colonic polyps in $18.9 \%$. We underlie that only 15 colonoscopies were performed, leading to a possible overall underestimation of polyps. Neoplasms were represented by medullar thyroid cancer $(2 / 10)$, neuroendocrine gastrointestinal tumor $(2 / 10)$, uterine $(2 / 10)$, colorectal (1/10), kidney (1/10), breast (1/10), and ovary $(1 / 10)$ cancer.

Neuroimaging was available in 45/53 (84.9\%) patients. The overall number of pituitary adenomas was $21 / 45$ (46.6\%, 
$4=$ macro and $17=$ microadenomas). Empty sella was present in $8 / 45$ (17.8\%), nonspecific alterations in 12/45 (26.7\%), and a completely normal finding was reported in 9/45 (20\%).

\section{Hormonal and clinical data of patients with and without acromegalic features}

Patients with acromegalic features (GR1) appeared clinically and hormonally different from the others (GR2), showing more comorbidities, more symptoms, and higher GHn values (details in Table 1). Acral enlargement was reported in all patients of GR1 according to inclusion criteria and in 2/28 of GR2 $(P<0.0001)$. Considering that some comorbidities are expected to increase with aging, we compared data on comorbidities in patients of similar age (we excluded 11 patients younger than 45 years, who all belonged to GR2).

MRI scan was available in 45/53 (21/25 of GR1, 24/28 of GR2). In GR1, MRI was performed because of the suspicion of acromegaly and revealed a pituitary adenoma in 9/21, empty sella in $2 / 21$, nonspecific signs in $6 / 21$, and normal findings in $4 / 21$. In GR1, the tumor mean diameter was $4.9 \pm 2.2 \mathrm{~mm}$, in GR2 $9.1 \pm 5.6 \mathrm{~mm}, P=0.073$.

Table 1 Clinical and hormonal features of patients with and without acromegalic features at the time of diagnosis of GH/IGF-1 discrepancy. IGF-1 values did not significantly differ between the two groups while patients with acromegalic features (GR1) displayed higher GH nadir levels and more comorbidities. Data are presented as median and IQRs.

\begin{tabular}{|c|c|}
\hline Parameters & GR1 \\
\hline Cases, $n$ & 25 \\
\hline Sex, F/M (\%) & $20 / 5(80)$ \\
\hline Age at diagnosis, years & $59(56.5-67.5)$ \\
\hline $\mathrm{BMI}, \mathrm{kg} / \mathrm{m}^{2}$ & $27.4 \pm 5$ \\
\hline HOMA-IR & $2.0 \pm 0.9$ \\
\hline \multicolumn{2}{|l|}{ Hormonal values } \\
\hline IGF-1, +SDS & $3.15(2.7-4.5)$ \\
\hline $\mathrm{GHn}, \mu \mathrm{g} / \mathrm{L}$ & $0.12(0.06-0.26)$ \\
\hline GHn (F menop), $\mu \mathrm{g} / \mathrm{L}$ & $0.12(0.07-0.23)$ \\
\hline GHn (F pre-menop), $\mu \mathrm{g} / \mathrm{L}$ & - \\
\hline $\mathrm{GHn}(\mathrm{M}), \mu \mathrm{g} / \mathrm{L}$ & $0.16(0.06-0.32)$ \\
\hline $\mathrm{GHr}, \mu \mathrm{g} / \mathrm{L}$ & $1.53(0.42-2.74)$ \\
\hline GHr (F menop), $\mu \mathrm{g} / \mathrm{L}$ & $1.83(1.41-4.9)$ \\
\hline GHr (F pre-menop), $\mu \mathrm{g} / \mathrm{L}$ & - \\
\hline $\mathrm{GHr}(\mathrm{M}), \mu \mathrm{g} / \mathrm{L}$ & $0.20(0.08-0.46)$ \\
\hline \multicolumn{2}{|l|}{ Acromegaly signs and symptoms } \\
\hline Acral enlargement, $n(\%)$ & $25(100)$ \\
\hline Paraesthesia, $n(\%)$ & $10(40)$ \\
\hline Arthralgia, $n(\%)$ & $10(40)$ \\
\hline Headache, $n(\%)$ & $7(28)$ \\
\hline Hyperhidrosis, $n(\%)$ & $3(12)$ \\
\hline \multicolumn{2}{|l|}{ Comorbidities (age > 45 years) } \\
\hline Cases ( $>45$ years), $n$ & 25 \\
\hline Age, years & $59(56.6-67.5)$ \\
\hline Comorbidities per patient, $n$ & $3(2-5)$ \\
\hline Goiter, $n(\%)$ & $13(52)$ \\
\hline Carpal tunnel, $n(\%)$ & $9(36)$ \\
\hline Colonic polyps, $n(\%)$ & $6(24)$ \\
\hline Malignancies, $n(\%)$ & $9(36)$ \\
\hline Hypertension, $n(\%)$ & $15(60)$ \\
\hline Cardiopathy, $n(\%)$ & $9(36)$ \\
\hline $\mathrm{DM}, n(\%)$ & $9(36)$ \\
\hline \multicolumn{2}{|l|}{ Pituitary MRI findings } \\
\hline MRI performed, $n$ & 21 \\
\hline Macro, $n(\%)$ & $2(9.5)$ \\
\hline Micro, $n(\%)$ & $7(33.3)$ \\
\hline Empty sella, $n(\%)$ & $2(9.5)$ \\
\hline
\end{tabular}

\begin{tabular}{|c|c|}
\hline GR2 & P-value \\
\hline \multicolumn{2}{|l|}{28} \\
\hline $14 / 14(50)$ & $0.02 *$ \\
\hline $52(31.5-60.5)$ & $<0.001 *$ \\
\hline $27.4 \pm 3.2$ & 0.1 \\
\hline $2.3 \pm 1$ & 0.5 \\
\hline $3.1(2.5-4)$ & 0.57 \\
\hline $0.05(0.04-0.08)$ & $0.002 *$ \\
\hline $0.06(0.04-0.06)$ & $0.04^{*}$ \\
\hline $0.12(0.05-0.24)$ & - \\
\hline $0.05(0.04-0.06)$ & $0.033^{*}$ \\
\hline $0.76(0.12-2.3)$ & 0.1 \\
\hline $1.19(0.96-2.9)$ & 0.29 \\
\hline $1.57(0.23-4.3)$ & - \\
\hline $0.13(0.05-1.18)$ & 0.36 \\
\hline $2(7.1)$ & $<0.0001 *$ \\
\hline $3(10.7)$ & $0.02 *$ \\
\hline $5(18)$ & 0.12 \\
\hline $4(14.3)$ & 0.34 \\
\hline $2(7.1)$ & 0.67 \\
\hline \multicolumn{2}{|l|}{17} \\
\hline 55 (52.5-69.5) & 0.26 \\
\hline $1(0-2)$ & $0.005^{*}$ \\
\hline $5(29)$ & 0.21 \\
\hline $1(6)$ & $0.031 *$ \\
\hline $3(18)$ & 0.72 \\
\hline $1(6)$ & 0.031 * \\
\hline $7(41)$ & 0.35 \\
\hline $5(29)$ & 0.75 \\
\hline $4(24)$ & 0.51 \\
\hline \multicolumn{2}{|l|}{24} \\
\hline $2(8.3)$ & $>0.99$ \\
\hline $10(41.7)$ & 0.76 \\
\hline $6(25)$ & 0.25 \\
\hline
\end{tabular}

DM, diabetes mellitus; F, female; GHn, GH nadir; GHr, GH random; GR1, group 1; GR2, group 2; M, male; macro, macroadenoma; menop, menopausal; micro, microadenoma; n, number; pre-menop, pre-menopausal. *statistically significant 


\section{Relationship between assessed parameters and comorbidities}

Spearman's rank correlation analysis revealed that GHn values were positively correlated with the number of comorbidities per patient (GHn: Spearman's $\rho=0.4$, $P=0.004)$ while GHr and IGF-1 were not $(P=0.4$ and $P=0.53$, respectively). This data on GHn are confirmed in the ANOVA analysis (Fig. 1). When patients were divided into five groups based on the number of comorbidities, a trend of GHn to increase is confirmed (test for linear trend between means: $\mathrm{F}=2.849, P=0.035$ ).

As expected, comorbidities were positively correlated with increasing age (Spearman's $\rho=0.56, P<0.0001$ ).

We performed ROC analysis to evaluate the presence of a GHn value which could suggest the presence of a high rate of acromegaly complications (at least three comorbidities). In the whole group, the ROC curve (area under the curve $(\mathrm{AUC})=0.761$ ) showed that the GHn cut-off of 0.1 $\mu \mathrm{g} / \mathrm{L}$ (Youden's J) pairs the highest sensitivity (71\%) and specificity $(77 \%)$ in the identification of a high rate of comorbidities (Fig. 2). In the whole group, the coexistence of acromegalic features and a $\mathrm{GHn} \geq 0.1 \mu \mathrm{g} / \mathrm{L}$ were strongly associated with the presence of a high rate of comorbidities

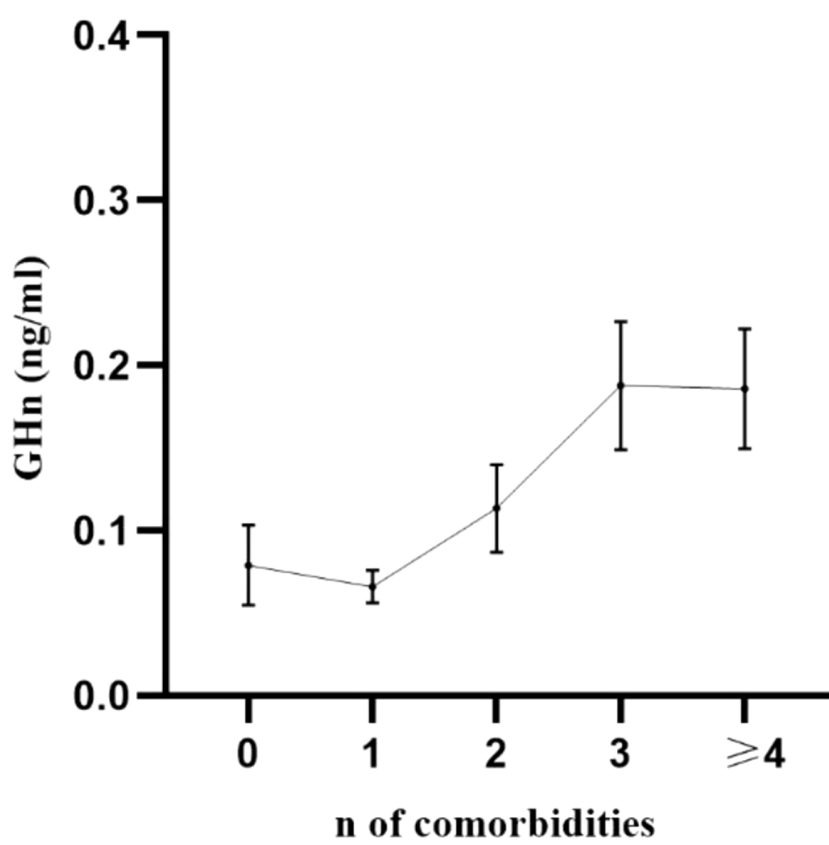

Figure 1

$\mathrm{GH}$ nadir shows a significant trend $(F=2.849, P=0.035)$ to increase according to the number of comorbidities per patient, even if $\mathrm{GH}$ nadir is lower than $0.4 \mathrm{ng} / \mathrm{mL}$. Data are expressed as mean \pm S.E.M. GHn, GH nadir; n, number. (at least three) with a sensitivity of $50 \%$ and specificity of $86 \%$ (OR of 6.0 with CI 1.421 to $22.61, P=0.02$ ).

\section{Follow up}

The mean follow-up was $5.7 \pm 3.4$ years (median $=6$ years). We registered an overall increase in the number of comorbidities per patient (median 3 vs $2, P=0.002$ ), especially in GR1 (GR1: median 4 vs 3 , IQR $3-5, P=0.04$; GR2: 1 vs 1 , IQR $0-3, P=0.06$ ). We observed an increase in some specific comorbidities: hypertension $+18 \%$, goitre $+5.7 \%$, overt $\mathrm{DM}+3.8 \%$, malignant neoplasms $+3.8 \%$, cardiopathy $+1.9 \%$. Eight new colonoscopies were performed, resulting in $+3.8 \%$ of colonic polyps (one polyp in a previous negative patient and one in a first screening). Carpal tunnel cases did not vary. Two patients with a previous malignancy were newly diagnosed with a different second neoplasm (one kidney and one lung cancer). We did not observe significant modifications in patients' signs and symptoms of acromegaly.

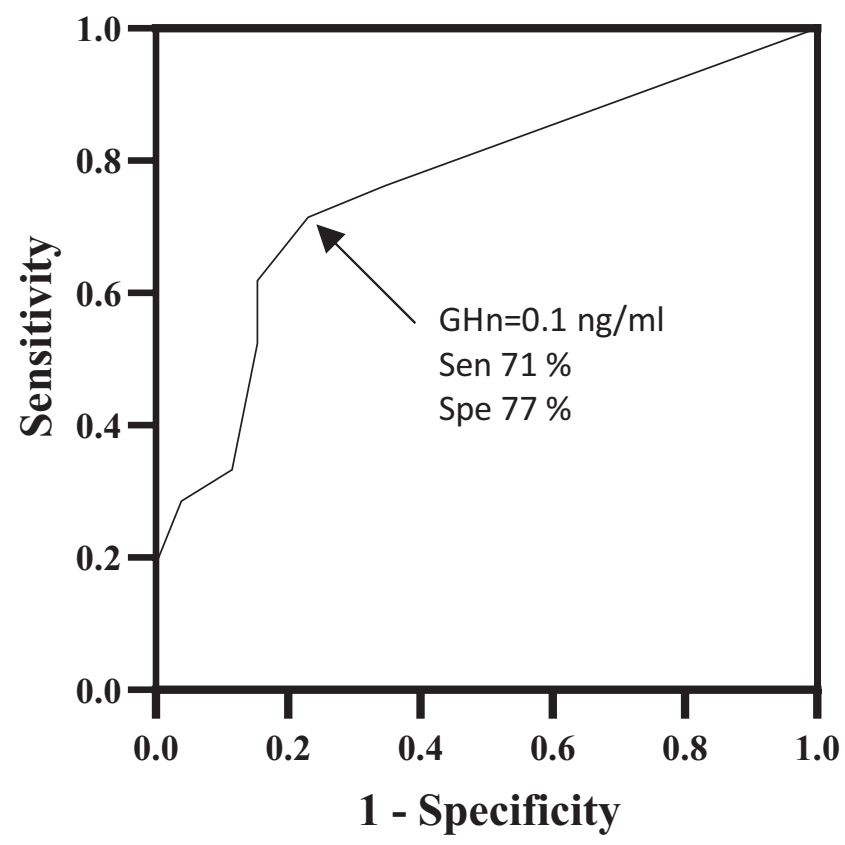

\section{Figure 2}

ROC curve of GH nadir levels for detecting the presence of a high rate of acromegalic comorbidities (at least three), $A \cup C=0.761, P=0.002$. The black square represents the $\mathrm{GH}$ nadir value of $0.1 \mathrm{ng} / \mathrm{mL}$ which showed the best combination of sensitivity and specificity for discriminating patients with and without a high rate of comorbidities (Sen $71 \%$ and Spe $77 \%)$. AUC, area under the curve; ROC, receiving operating characteristic; Sen, sensitivity; Spe, specificity. 

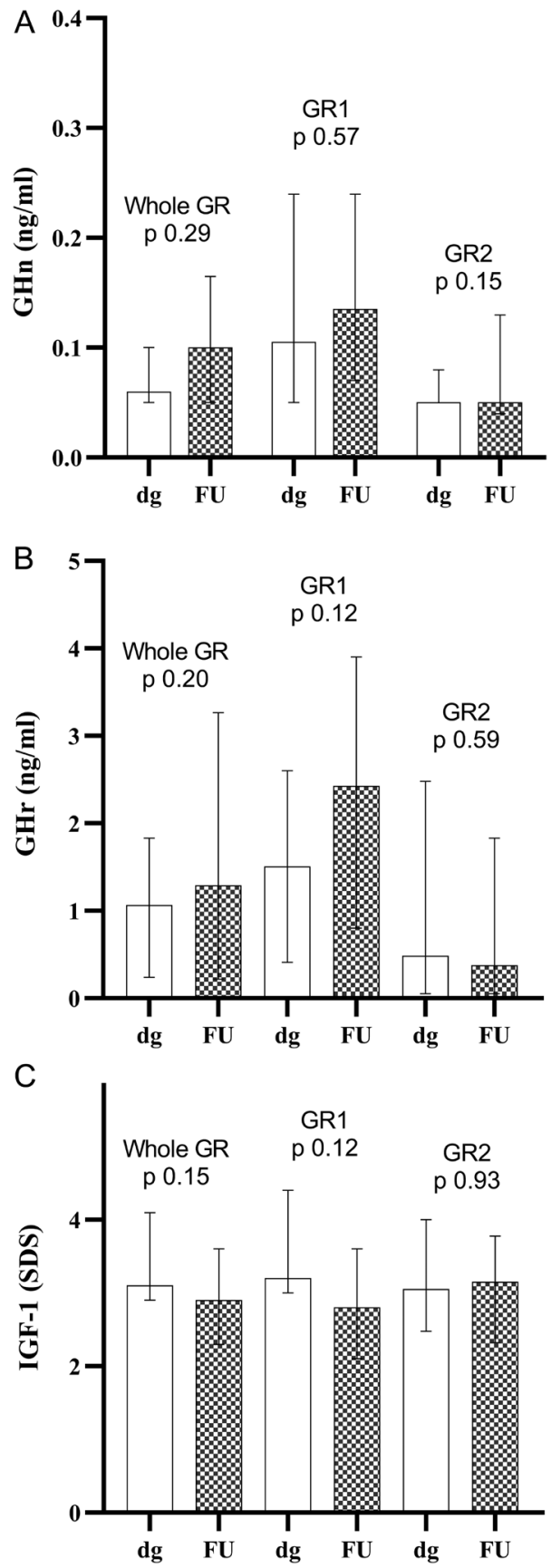

\section{Figure 3}

Hormonal evaluations at diagnosis (DG) and at the last available follow-up (FU). Mean FU time was $5.7 \pm 3.4$ years and we did not observe any significant modifications in $\mathrm{GHn}(\mathrm{A})$, GHr (B) and IGF-1 (C) values. These data confirm that our group of patients did not present acromegaly in its early stage but a 'low GH' acromegaly, characterized by stable GH and persistently high IGF-1 levels. Data are expressed as median with IQR range. GHn, GH nadir; GHr, GH random; dg, diagnosis; FU, follow-up; Whole GR, whole group of patients; GR1, group 1; GR2, group 2.
Interestingly, IGF-1 and GH levels did not significantly change, both in the whole group and subgroups (GR1: $\mathrm{GHn}+0.045, P=0.570$; $\mathrm{GHr}+1.58, P=0.12$; IGF-1 -0.72 , $P=0.123$. GR2: $\mathrm{GHn}+0.02, P=0.15 ; \mathrm{GHr}+0.08, P=0.594$; IGF-1 +0.01, $P=0.93$ ) (Fig. 3).

A neuroradiological follow-up was available in 31/45 patients with a previous MRI. We found five new microadenomas (three in GR1, two in GR2; maximum diameter range: $2.5-4 \mathrm{~mm}$ ). The clinical, hormonal, and neuroradiological findings of all patients, are reported in the Supplementary Table (see Supplementary materials section provided at the end of the article).

\section{Treatment}

One patient, presenting a macroadenoma and an ACTHdependent hypercortisolism in addition to acromegalic features, was treated with TNS surgery. The histological report showed an ACTH+/GH+/LH-/FSH-/PRL-/ TSH- immunostaining. After surgery, we observed a normalization of IGF-1 and cortisollevels. Onemorepatient, with acromegalic features and no evidence of adenoma, was treated with somatostatin analogs (octreotide LAR 30 mg every 28 days) with good disease control. This patient previously underwent a Ga 68-DOTANOC PET imaging which resulted negative for ectopic hormonal secretion. According to our data showing a high rate of acromegalic comorbidities in GR1, other patients are currently under evaluation for a therapeutic option (medical treatment or surgery depending on the result of pituitary MRI).

\section{Discussion}

In 2002, Barkan and coworkers introduced the term 'micromegaly' and, in the following years, other studies described similar patients characterized by acromegalic features, high IGF-1, but inappropriately low GH levels (7, $8,9,11,14,32,33)$. Every study had a different design and aim, and GH nadir cut-off differed according to various guidelines, ranging from $2 \mu \mathrm{g} / \mathrm{L}$ to the most recent value of $0.4 \mu \mathrm{g} / \mathrm{L}$. Therefore, it is likely that we would now define a lot of patients previously considered 'micromegalic' as acromegalic $(7,8,9,14)$. In the following paragraph, we describe the most relevant clinical observations collected in the literature.

In 2002, sixteen acromegalic patients showing a GHn $<2 \mu \mathrm{g} / \mathrm{L}$ were reported, noting that 24 -h mean GH values overlapped with healthy controls (14). Similarly, Ribeiro et al. in 2011, described seven acromegalic patients 
with GHn $<0.4 \mu \mathrm{g} / \mathrm{L}$ and a 'low 24-h GH profile' (17). All these patients had a histologically confirmed GH secreting pituitary microadenoma. In 2012, Subbarayan et al. confirmed the presence of few patients with a $\mathrm{GHn}<0.4 \mu \mathrm{g} / \mathrm{Lin}$ a group treated with TNS (9). Interestingly, in the study of Espinosa et al., all acromegalic patients with GHn $<0.4 \mu \mathrm{g} / \mathrm{L}$ (three cases) showed a persistent disease after treatment (11).

Our study described a large cohort presenting with high IGF-1 and GHn $<0.4 \mu \mathrm{g} / \mathrm{L}$. The group with acromegalic features, which we can also define as the 'micromegalic group', presented a higher prevalence of acromegalic comorbidities which is similar to the one reported in acromegaly $(34,35,36,37,38,39,40,41)$. Unfortunately, this is a retrospective study, and the number of diseases could be under-estimated, above all colonic polyps as few colonoscopies were performed. On the contrary, the age at diagnosis in this group was higher than expected in acromegaly (59 years vs $40-50$ years) $(42,43,44)$.

Follow-up data showed that both IGF-1 and GH levels remained stable while the prevalence of comorbidities significantly increased in the 'micromegalic group'. The main bias of this observation could be the expected health deterioration with aging, although the time of follow-up does not seem to be sufficient to justify such an increase. In our view, these data indicate that 'micromegaly' constitutes a distinct clinical entity, not being attributable to 'classic' acromegaly in its early stages.

Unlike previous studies showing a pituitary adenoma in almost all micromegalic patients, we found confirmatory imaging in only $57 \%$ (GR1). Nevertheless, this prevalence is higher than expected in the general population, especially for macroadenomas (9.5\% vs $0.16-0.3 \%$ ) (45, $46)$, suggesting the presence of a pituitary disorder. We also observed an increase in diagnoses of microadenomas during the follow-up period, speculating both on the improved MRI performance or on a real increase in adenoma's volume. The low rate of macroadenomas in these patients, as previously described (7), confirms a different clinical presentation from classical acromegalic patients who mostly present with large lesions and only occasionally with negative MRI. The absence of a clear adenomatous area might represent a challenge for TNS surgery, as frequently faced in Cushing disease, but no large data on outcomes have been collected so far.

In our series, we described numerous patients with high IGF-1 levels despite no clear clinical suspicion of acromegaly (GR2). These patients were screened for $\mathrm{GH}$ hypersecretion mainly for the presence of another concomitant pituitary alteration. With respect to this group, IGF-1 evaluation harbors some limitations of its own as the lack of adequate age-adjusted normative data and susceptibility to interference from IGFBP. The lower incidence of acromegalic comorbidities in this group as well as in previous studies (9) supports the idea of an incidental finding with uncertain clinical significance. Likewise, higher GH levels in GR1 seem to support the presence of a GH-related disease in GR1 but not in GR2.

Various authors pointed out many uncertainties about the exact cut-off of GH nadir after OGTT, according to evidence on micromegalic patients. Some series also highlighted the need for individualization of reference values, according to gender, age, and BMI $(31,47)$. We could not confirm the presence of a GH-producing tumor in our series (except in one patient with an ACTH-GH co-hypersecretion) thus we were not able to associate a GHn cut-off value with the histological confirmation of disease. However, we identified $0.1 \mu \mathrm{g} / \mathrm{L}$ as the optimal cut-off to predict the presence of a high rate of acromegalic comorbidities in the setting of a condition previously identified as IGF-1/GH discrepancy. The combination of a GHn $\geq 0.1 \mu \mathrm{g} / \mathrm{L}$ and acromegalic features enhances the specificity in predicting the presence of multiple comorbidities (specificity $=86 \%$ ). We, therefore, suggest a screening of acromegalic comorbidities in patients with these two characteristics.

Since GH hypersecretion has rarely an ectopic origin, we performed 68-Gallium imaging in one patient with a normal MRI and the exam resulted negative for abnormal uptakes (2). Considering that ectopic acromegaly is generally associated with very high GH levels (48), we decided not to undergo the other patients this expensive evaluation.

The pathophysiology of this 'low GH' acromegaly remains mostly unclear. It was pointed out by some authors that continuous exposure of the liver and other tissues to even minimally elevated tonic GH levels is enough to increase IGF-1 production into a supernormal range (12, 14). It is possible that these patients present a mildly high rate of GH production but tonic and sufficient to increase IGF-1 levels. A possible enhanced peripheral sensitivity to $\mathrm{GH}$ has also been postulated in some patients, for example in the presence of specific GH-receptor isoforms such as d3-GHr, which is proven to be associated with higher IGF-1 levels in patients treated with rGH $(49,50)$. Furthermore, with common GH assays, we mainly measure the $22-\mathrm{k}$ circulating polypeptide, thus we cannot exclude the possible secretion of other active and not detected GH isoforms by the pituitary gland. However, no consistent evidence regarding all these hypotheses is available yet. 


\section{Conclusions}

In conclusion, patients with 'micromegaly', even in the presence of suppressed GH levels, present a high rate of comorbidities, showing no clinical differences from those with acromegaly. According to this evidence, we advise a revision of the GH nadir cut-off that, as already proposed, takes into consideration available assays and the patient's characteristics (especially sex, estrogen status, and BMI). Considering the well-known impact of acromegalic complications on the quality of life and mortality, we suggest considering these patients as acromegalic, applying the same screening program to detect comorbidities and maintaining a close follow-up. Treatment should also be considered in selected patients. Additional data are needed in order to identify the precise pathophysiology of this 'low GH acromegaly' and to point out the best management.

\section{Supplementary materials}

This is linked to the online version of the paper at https://doi.org/10.1530/ EJE-21-0024.

\section{Declaration of interest}

The authors declare that there is no conflict of interest that could be perceived as prejudicing the impartiality of this study.

\section{Funding}

This work was supported by Ricerca Corrente funds from Fondazione IRCCS Ca' Granda Ospedale Maggiore Policlinico and partially supported by grant NET-2018-12365454 from the Italian Ministry of Health and Regione Lombardia.

\section{References}

1 Vilar L, Vilar CF, Lyra R, Lyra R \& Naves LA. Acromegaly: clinical features at diagnosis. Pituitary 201720 22-32. (https://doi.org/10.1007/ s11102-016-0772-8)

2 Katznelson L, Laws ER, Melmed S, Molitch ME, Murad MH, Utz A, Wass JAH \& Endocrine Society. Acromegaly: an Endocrine Society clinical practice guideline. Journal of Clinical Endocrinology and Metabolism 201499 3933-3951. (https://doi.org/10.1210/jc.2014-2700)

3 Arosio M, Reimondo G, Malchiodi E, Berchialla P, Borraccino A, Marinis L De, Pivonello R, Grottoli S, Losa M, Cannavò S et al. Predictors of morbidity and mortality in acromegaly: an Italian survey. European Journal of Endocrinology 2012167 189-198. (https://doi. org/10.1530/EJE-12-0084)

4 Maione L, Brue T, Beckers A, Delemer B, Petrossians P, Borson-Chazot F, Chabre O, François P, Bertherat J, Cortet-Rudelli C et al. Changes in the management and comorbidities of acromegaly over three decades: the French Acromegaly Registry. European Journal of Endocrinology 2017 176 645-655. (https://doi.org/10.1530/EJE-16-1064)

5 Kasuki L, Rocha PdaS, Lamback EB \& Gadelha MR. Determinants of morbidities and mortality in acromegaly. Archives of Endocrinology and Metabolism 202063 630-637. (https://doi.org/10.20945/2359. 3997000000193)

6 Ritvonen E, Löyttyniemi E, Jaatinen P, Ebeling T, Moilanen L, Nuutila P, Kauppinen-Mäkelin R \& Schalin-Jäntti C. Mortality in acromegaly: a 20-year follow-up study. Endocrine-Related Cancer 2016 23 469-480. (https://doi.org/10.1530/ERC-16-0106)

7 Mercado M, Espinosa de los Monteros AL, Sosa E, Cheng S, Mendoza V, Hernández I, Sandoval C, Guinto G \& Molina M. Clinical-biochemical correlations in acromegaly at diagnosis and the real prevalence of biochemically discordant disease. Hormone Research 200462 293-299. (https://doi.org/10.1159/000082032)

8 Machado EO, Taboada GF, Neto LV, Haute FR van, Corrêa LL, Balarini GA, Shrank Y, Goulart M \& Gadelha MR. Prevalence of discordant GH and IGF-I levels in acromegalics at diagnosis, after surgical treatment and during treatment with octreotide LAR ${ }^{\oplus}$. Growth Hormone and IGF Research 200818 389-393. (https://doi.org/10.1016/j.ghir.2008.02.001)

9 Subbarayan SK, Fleseriu M, Gordon MB, Brzana JA, Kennedy L, Faiman C, Hatipoglu BA, Prayson RA, Delashaw JB, Weil RJ et al. Serum IGF-1 in the diagnosis of acromegaly and the profile of patients with elevated IGF-1 but normal glucose-suppressed growth hormone. Endocrine Practice 2012 18 817-825. (https://doi.org/10.4158/EP11324.OR)

10 Schilbach K, Stormann S, Bidlingmaier M \& Schopohl J. A case of 'micromegaly': need for revision of oral glucose tolerance test (OGTT) cut-offs with modern growth hormone assays in acromegaly. Endocrine Abstracts 201963 P252. (https://doi.org/10.1530/endoabs.63.P252)

11 Espinosa De Los Monteros AL, Sosa-Eroza E, Gonzalez B, Mendoza V \& Mercado M. Prevalence, clinical and biochemical spectrum, and treatment outcome of acromegaly with normal basal gh at diagnosis. Journal of Clinical Endocrinology and Metabolism 2018103 3919-3924. (https://doi.org/10.1210/jc.2018-01113)

12 Butz LB, Sullivan SE, Chandler WF \& Barkan AL. 'Micromegaly': an update on the prevalence of acromegaly with apparently normal GH secretion in the modern era. Pituitary 201619 547-551. (https://doi. org/10.1007/s11102-016-0735-0)

13 , , , , Shimon I, Nass D \& Hadani M. Acromegaly with normal growth hormone levels: response to Sandostatin-LAR treatment. Pituitary 20002289 294. (https://doi.org/10.1023/a:1009965201451)

14 Dimaraki EV, Jaffe CA, Demott-Friberg R, Chandler WF \& Barkan AL. Acromegaly with apparently normal GH secretion: implications for diagnosis and follow-up. Journal of Clinical Endocrinology and Metabolism 200287 3537-3542. (https://doi.org/10.1210/ jcem.87.8.8658)

15 Freda PU, Beckers AM, Katznelson L, Molitch ME, Montori VM, Post KD, Vance ML \& Endocrine Society. Pituitary incidentaloma: an Endocrine Society clinical practice guideline. Journal of Clinical Endocrinology and Metabolism 201196 894-904. (https://doi. org/10.1210/jc.2010-1048)

16 Junnila RK, Strasburger CJ \& Bidlingmaier M. Pitfalls of insulinlike growth factor-I and growth hormone assays. Endocrinology and Metabolism Clinics of North America 201544 27-34. (https://doi. org/10.1016/j.ecl.2014.10.003)

17 Ribeiro-Oliveira A, Faje AT \& Barkan AL. Limited utility of oral glucose tolerance test in biochemically active acromegaly. European Journal of Endocrinology 2011 164 17-22. (https://doi.org/10.1530/EJE-10-0744)

18 Freda PU, Reyes CM, Nuruzzaman AT, Sundeen RE \& Bruce JN. Basal and glucose-suppressed GH levels less than $1 \mu \mathrm{g} / \mathrm{L}$ in newly diagnosed acromegaly. Pituitary 20036 175-180. (https://doi.org/10.1023/ B:PITU.0000023424.72021.e2)

19 Melmed S. Acromegaly pathogenesis and treatment. Journal of Clinical Investigation 20091193189 - 3202. (https://doi.org/10.1172/ JCI39375DS1)

20 Giustina A, Chanson P, Bronstein MD, Klibanski A, Lamberts S, Casanueva FF, Trainer P, Ghigo E, Ho K, Melmed S et al. A consensus on criteria for cure of acromegaly. Journal of Clinical Endocrinology and Metabolism 201095 3141-3148. (https://doi.org/10.1210/jc.2009-2670)

21 Freda PU. Current concepts in the biochemical assessment of the patient with acromegaly. Growth Hormone and IGF Research 200313 171-184. (https://doi.org/10.1016/S1096-6374(03)00029-7)

22 Melmed S. Medical progress: acromegaly. New England Journal of Medicine 2006355 2558-2573. (https://doi.org/10.1056/NEJMra062453) 
23 Chanson P, Salenave S \& Kamenicky P. Acromegaly. In Handbook of Clinical Neurology, pp. 197-219. Elsevier, 2014.

24 Colao A, Ferone D, Marzullo P \& Lombardi G. Systemic complications of acromegaly: epidemiology, pathogenesis, and management. Endocrine Reviews 200425 102-152. (https://doi.org/10.1210/er.2002-0022)

25 Petrossians P, Daly AF, Natchev E, Maione L, Blijdorp K, SahnounFathallah M, Auriemma R, Diallo AM, Hulting AL, Ferone D et al. Acromegaly at diagnosis in 3173 patients from the Liège Acromegaly Survey (LAS) Database. Endocrine-Related Cancer 201724 505-518. (https://doi.org/10.1530/ERC-17-0253)

26 Delhougne B, Deneux C, Abs R, Chanson P, Fierens H, Laurent-Puig P, Duysburgh I, Stevenaert A, Tabarin A, Delwaide J et al. The prevalence of colonic polyps in acromegaly: a colonoscopic and pathological study in 103 patients. Journal of Clinical Endocrinology and Metabolism 199580 3223-3226. (https://doi.org/10.1210/jcem.80.11.7593429)

27 Terzolo M, Reimondo G, Berchialla P, Ferrante E, Malchiodi E, De Marinis L, Pivonello R, Grottoli S, Losa M, Cannavo S et al. Acromegaly is associated with increased cancer risk: a survey in Italy. EndocrineRelated Cancer 201724 495-504. (https://doi.org/10.1530/ERC-16-0553)

28 Ben-Shlomo A \& Melmed S. Acromegaly. Endocrinology and Metabolism Clinics of North America 200837 101-122, viii. (https://doi. org/10.1016/j.ecl.2007.10.002)

29 Matthews DR, Hosker JP, Rudenski AS, Naylor BA, Treacher DF \& Turner RC. Homeostasis model assessment: insulin resistance and beta-cell function from fasting plasma glucose and insulin concentrations in man. Diabetologia 198528 412-419. (https://doi. org/10.1007/BF00280883)

30 Chanson P, Arnoux A, Mavromati M, Brailly-Tabard S, Massart C, Young J, Piketty ML, Souberbielle JC \& VARIETE Investigators. Reference values for IGF-I serum concentrations: comparison of six immunoassays. Journal of Clinical Endocrinology and Metabolism 2016 $1013450-3458$. (https://doi.org/10.1210/jc.2016-1257)

31 Schilbach K, Gar C, Lechner A, Nicolay SS, Schwerdt L, Haenelt M, Dal J, Jørgensen JL, Störmann S, Schopohl J et al. Determinants of the growth hormone nadir during oral glucose tolerance test in adults. European Journal of Endocrinology 2019181 55-67. (https://doi. org/10.1530/EJE-19-0139)

32 Abreu A, Tovar AP, Castellanos R, Valenzuela A, Giraldo CMG, Pinedo AC, Guerrero DP, Barrera CAB, Franco HI, Ribeiro-Oliveira A et al. Challenges in the diagnosis and management of acromegaly: a focus on comorbidities. Pituitary 201619 448-457. (https://doi. org/10.1007/s11102-016-0725-2)

33 Ribeiro de Oliveira Longo Schweizer J, Ribeiro-Oliveira Jr A \& Bidlingmaier M. Growth hormone: isoforms, clinical aspects and assays interference. Clinical Diabetes and Endocrinology 2018418. (https://doi.org/10.1186/s40842-018-0068-1)

34 Gasperi M, Martino E, Manetti L, Arosio M, Porretti S, Faglia G, Mariotti S, Colao AM, Lombardi G, Baldelli R et al. Prevalence of thyroid diseases in patients with acromegaly: results of an Italian Multi-center Study. Journal of Endocrinological Investigation 200225 240-245. (https://doi.org/10.1007/BF03343997)

35 Oktayoglu P, Nas K, Kilinç F, Tasdemir N, Bozkurt M \& Yildiz I. Assessment of the presence of carpal tunnel syndrome in patients with diabetes mellitus, hypothyroidism and acromegaly. Journal of Clinical and Diagnostic Research 20159 OC14-OC18. (https://doi.org/10.7860/ JCDR/2015/13149.6101)

36 Rokkas T, Pistiolas D, Sechopoulos P, Margantinis G \& Koukoulis G. Risk of colorectal neoplasm in patients with acromegaly: a metaanalysis. World Journal of Gastroenterology 200814 3484-3489. (https:// doi.org/10.3748/wig.14.3484)
37 Wolinski K, Czarnywojtek A, Ruchala M, Mulrow C \& Gotzsche P. Risk of thyroid nodular disease and thyroid cancer in patients with acromegaly - meta-analysis and systematic review. PLoS ONE 20149 e88787. (https://doi.org/10.1371/journal.pone.0088787)

38 Puglisi S \& Terzolo M. Hypertension and acromegaly. Endocrinology and Metabolism Clinics of North America 201948 779-793. (https://doi. org/10.1016/j.ecl.2019.08.008)

39 Pereira AM, Van Thiel SW, Lindner JR, Roelfsema F, Van Der Wall EE, Morreau H, Smit JWA, Romijn JA \& Bax JJ. Increased prevalence of regurgitant valvular heart disease in acromegaly. Journal of Clinical Endocrinology and Metabolism 200489 71-75. (https://doi.org/10.1210/ jc.2003-030849)

40 Clayton RN. Cardiovascular function in acromegaly. Endocrine Reviews 200324 272-277. (https://doi.org/10.1210/er.2003-0009)

41 Kahaly G, Olshausen KV, Mohr-Kahaly S, Erbel R, Boor S, Beyer J \& Meyer J. Arrhythmia profile in acromegaly. European Heart Journal 1992 13 51-56. (https://doi.org/10.1093/oxfordjournals.eurheartj.a060047)

42 Daly AF, Rixhon M, Adam C, Dempegioti A, Tichomirowa MA $\&$ Beckers A. High prevalence of pituitary adenomas: a crosssectional study in the province of Liege, Belgium. Journal of Clinical Endocrinology and Metabolism 200691 4769-4775. (https://doi. org/10.1210/jc.2006-1668)

43 Dal J, Feldt-Rasmussen U, Andersen M, Kristensen LØ, Laurberg P, Pedersen L, Dekkers OM, Sørensen HT \& Jørgensen JOL. Acromegaly incidence, prevalence, complications and long-term prognosis: a nationwide cohort study. European Journal of Endocrinology 2016175 181-190. (https://doi.org/10.1530/EJE-16-0117)

44 Fernandez A, Karavitaki N \& Wass JAH. Prevalence of pituitary adenomas: a community-based, cross-sectional study in Banbury (Oxfordshire, UK). Clinical Endocrinology 201072 377-382. (https:// doi.org/10.1111/j.1365-2265.2009.03667.x)

45 Yue NC, Longstreth WT, Elster AD, Jungreis CA, O'Leary DH \& Poirier VC. Clinically serious abnormalities found incidentally at MR imaging of the brain: data from the Cardiovascular Health Study. Radiology 1997202 41-46. (https://doi.org/10.1148/ radiology.202.1.8988190)

46 Vernooij MW, Ikram MA, Tanghe HL, Vincent AJPE, Hofman A, Krestin GP, Niessen WJ, Breteler MMB \& van der Lugt A. Incidental findings on brain MRI in the general population. New England Journal of Medicine 2007357 1821-1828. (https://doi.org/10.1056/NEJMoa070972)

47 Arafat AM, Möhlig M, Weickert MO, Perschel FH, Purschwitz J, Spranger J, Strasburger CJ, Schöfl C \& Pfeiffer AFH. Growth hormone response during oral glucose tolerance test: the impact of assay method on the estimation of reference values in patients with acromegaly and in healthy controls, and the role of gender, age, and body mass index. Journal of Clinical Endocrinology and Metabolism 2008 93 1254-1262. (https://doi.org/10.1210/jc.2007-2084)

48 Faglia G, Arosio M \& Bazzoni N. Ectopic acromegaly. Endocrinology and Metabolism Clinics of North America 199221 575-595. (https://doi. org/10.1016/S0889-8529(18)30203-2)

49 Cinar N, Dagdelen S, Yorgun H, Canpolat U, Kabakçı G \& Erbas T. The clinical and cardiometabolic effects of d3-growth hormone receptor polymorphism in acromegaly. Pituitary 201518 116-125. (https://doi. org/10.1007/s11102-014-0564-y)

50 Marchisotti FG, Jorge AAL, Montenegro LR, Berger K, de Carvalho LRS, Mendonca BB \& Arnhold IJP. Comparison between weight-based and IGF-I-based growth hormone (GH) dosing in the treatment of children with GH deficiency and influence of exon 3 deleted GH receptor variant. Growth Hormone and IGF Research 200919 179-186. (https:// doi.org/10.1016/j.ghir.2008.10.001)

Received 11 January 2021

Revised version received 20 April 2021

Accepted 3 June 2021 